\title{
Characterization of pressure-mediated vascular tone in resistance arteries from bile duct-ligated rats
}

\author{
Ravirajsinh N. Jadeja ${ }^{1}$, Menaka C. Thounaojam ${ }^{2}$ and Sandeep Khurana ${ }^{1}$ \\ ${ }^{1}$ Digestive Health Center, Medical College of Georgia, Augusta, GA, USA \\ ${ }^{2}$ Department of Biochemistry and Cancer Biology, School of Medicine, Meharry Medical College, Nashville, TN, USA \\ Correspondence to: Sandeep Khurana, email: skhurana@geisinger.edu \\ Keywords: cirrhosis, portal hypertension, myogenic tone, vascular dysfunction, mesenteric arteries, Pathology Section \\ Received: August 19, $2016 \quad$ Accepted: February 01, $2017 \quad$ Published: February 16, 2017
}

Copyright: Jadeja et al. This is an open-access article distributed under the terms of the Creative Commons Attribution License (CC-BY), which permits unrestricted use, distribution, and reproduction in any medium, provided the original author and source are credited.

\section{ABSTRACT}

In cirrhosis, changes in pressure-mediated vascular tone, a key determinant of systemic vascular resistance (SVR), are unknown. To address this gap in knowledge, we assessed ex vivo dynamics of pressurized mesenteric resistance arteries (diameter $260 \mu \mathrm{m}$ ) from bile duct-ligated (BDL) and sham-operated (SHAM) rats and determined the underlying mechanisms. At isobaric intraluminal pressure (70 $\mathrm{mmHg}$ ) as well as with step-wise increase in pressure $(10-110 \mathrm{mmHg})$, arteries from SHAM-rats constricted more than BDL-rats, and had reduced luminal area. In both groups, incubation with LNAME (a NOS inhibitor) had no effect on pressure-mediated tone, and expression of NOS isoforms were similar. TEA, which enhances $\mathrm{Ca}^{2+}$ influx, augmented arterial tone only in SHAM-rats, with minimal effect in those from BDL-rats that was associated with reduced expression of $\mathrm{Ca}^{2+}$ channel TRPC6. In permeabilized arteries, high-dose $\mathrm{Ca}^{2+}$ and yGTP enhanced the vascular tone, which remained lower in BDL-rats that was associated with reduced ROCK2 and PMLC expression. Further, compared to SHAM-rats, in BDL-rats, arteries had reduced collagen expression which was associated with increased expression and activity of MMP-9. BDL-rats also had increased plasma reactive oxygen species (ROS). In vascular smooth muscle cells in vitro, peroxynitrite enhanced MMP-9 activity and reduced ROCK2 expression. These data provide evidence that in cirrhosis, pressure-mediated tone is reduced in resistance arteries, and suggest that circulating $\mathrm{ROS}$ play a role in reducing $\mathrm{Ca}^{2+}$ sensitivity and enhancing elasticity to induce arterial adaptations. These findings provide insights into mechanisms underlying attenuated SVR in cirrhosis.

\section{INTRODUCTION}

Cirrhosis is characterized by contrasting changes in intrahepatic and extra-hepatic vascular beds-intrahepatic vascular resistance increases while systemic vascular resistance (SVR) decreases [1, 2]. These hemodynamic changes lead to portal hypertension (PHT), and arterial hypotension, respectively. Increased intrahepatic vascular resistance contributes to development of complications such as gastro-esophageal varices and ascites, and at the same time, attenuated SVR not only reduces renal perfusion that promotes fluid retention, but also impedes our ability to treat those complications. For example, to reduce PHT and risk of variceal bleeding, $\beta$-blockers are used to impede the increase in portal blood inflow ( $\beta_{2}$-effect). However, due to the effect of $\beta$-blockers on systemic vascular beds, already reduced-SVR may decrease further. The resulting arterial under-filling further attenuates renal perfusion and enhances fluid retention [3]. Therefore, in patients with cirrhosis, arterial hypotension and reduced SVR are critical barriers to pharmacological approaches to reduce intrahepatic vascular resistance and treat PHT.

Hemodynamic changes in murine models of cirrhosis mimic those in humans. Previous studies indicated that in the arteries from cirrhotic animals, agonist-induced contractility is reduced [4-6]; the implicated mechanisms include increased vascular nitric 
oxide (NO) and carbon monoxide, reduced vascular smooth muscle (VSM) $\mathrm{Ca}^{2+}$ influx, and reduced expression of $\mathrm{Ca}^{2+}$ sensitization proteins [7, 8]. However, most previous assessments were made in conduit arteries (e.g. aorta or superior mesenteric arteries), which are not the primary determinants of SVR. These studies also relied on isometric techniques (wire-myography), results of which may differ substantially from those obtained by pressuremyography [9]. Therefore, despite these advances in our understanding of mechanisms underlying vascular changes in cirrhosis, little is known about changes in vascular dynamics of small resistance arteries.

Small resistance arteries (diameter $<300 \mu \mathrm{m}$ ) are major determinants of SVR. The resistance artery smooth muscle has an intrinsic ability to constrict in response to increase in intraluminal pressure [10]. This feature, which is independent of endothelium and neurohumoral input, is not only a key determinant of SVR but also of local blood flow and tissue perfusion. The mechanisms underlying pressure-mediated vascular tone involve intracellular $\mathrm{Ca}^{2+}$ influx via $\mathrm{Ca}^{2+}$ channels, and $\mathrm{Ca}^{2+}$ sensitization by Rhoassociated protein kinase (ROCK) and protein kinase $\mathrm{C}$ (PKC) pathways [11]. We demonstrated previously that the small mesenteric arteries from rats, in isobaric conditions, develop stable vasoconstriction known as myogenic tone (MT), and with step-wise increase in intraluminal pressure, constrict, a phenomenon known as myogenic response (MR) $[12,13]$.

Both MT and MR are excellent surrogates for systemic vascular resistance (SVR). In cirrhosis, SVR and arterial blood pressures are reduced; however, changes in MT and MR are unknown. We hypothesize that in cirrhosis, MT and MR are attenuated. To address these gaps in knowledge, and test our hypothesis, we investigated ex vivo changes in pressure-mediated vascular tone in the $4^{\text {th }}$-order mesenteric resistance arteries from BDL-rats, a validated model of cirrhosis [8, 14-18], and investigated the underlying mechanisms.

\section{RESULTS}

\section{In BDL-rats, myogenic tone and myogenic response are reduced}

Bile duct ligation in rats induces cirrhosis and development of ascites as outlined in supplementary material. The mesenteric arteries isolated from BDL- and SHAM-rats were pressurized at $70 \mathrm{mmHg}$ and allowed to develop spontaneous constriction. As shown in Figure $1 \mathrm{~A}$, the arteries from the SHAM-rats constricted more than those from the BDL-rats $(27 \pm 6 \%$ vs. $6 \pm 1 \% \mathrm{PD}$, respectively). Figure $1 \mathrm{~B}$ shows changes in arterial diameter. To determine MR, the intraluminal pressure was increased in a step-wise manner $(10-110 \mathrm{mmHg})$ and the arterial diameter recorded at each step. With increasing pressure, the arteries from the SHAM-rats constricted, however, those from the BDL-rats did not (Figures 1C $\&$ 1D). These data indicated that in the arteries from the BDL-rats, autoregulatory response was markedly attenuated.

\section{In BDL-rats, reduced myogenic response is independent of nitric oxide (NO)}

In cirrhosis, increased vascular NO is implicated in agonist-mediated hypocontractility as well increased acetylcholine-mediated relaxation [19]. Therefore, to assess the role of $\mathrm{NO}$ in pressure-mediated vascular tone, we assessed the role of $\mathrm{NO}$ in modulating MR, by incubating the arteries with $300 \mu \mathrm{M}$ LNAME (a nonselective NOS inhibitor) for at least $1 \mathrm{~h}$. Incubation of SHAM and BDL arteries with L-NAME led to no significant effect on the diameter when compared to non L-NAME treated groups respectively (Figures 2A \& 2B). Further, pressure-induced myogenic tone in presence and absence of L-NAME remained similar in both groups (Figure 2C). In both groups, arterial expression of mRNA for NOS isoforms (iNOS, eNOS and nNOS) was similar (Figure 2D). The protein expression of eNOS was confirmed by immunoblotting (Figure 2E), however that of iNOS and nNOS was too small to quantify (data not shown). These results indicated that after BDL, there is no change in NOS expression in small mesenteric arteries. Further, in small mesenteric arteries, local NO has no role in modulating pressure-mediated vascular tone.

\section{In BDL-rats, agonist-mediated vasoconstriction is reduced}

In the pressurized arteries from BDL-rats, $10 \mu \mathrm{M}$ U46619 (a synthetic thromboxane A2 receptor agonist $[20,21])$-mediated constriction was reduced compared to SHAM-rats $(57.4 \pm 4.4 v s .77 \pm 1.4 \% \mathrm{PD}$, Figure $3 \mathrm{~A})$. Incubation with $300 \mu \mathrm{M}$ L-NAME for $60 \mathrm{~min}$ enhanced U46619-mediated constriction only in the SHAM-rats and had no effect in the BDL-rats (Figure 3A). Changes in arterial diameter are shown in Figures $3 \mathrm{~B} \& 3 \mathrm{C}$. These results a) validated that in the BDL-model of cirrhosis, agonist-induced constriction is reduced and b) indicated that in normal physiological state, there is a possible interactions between $\mathrm{NO}$ and agonist-induced signaling, which is lost in cirrhosis [22].

Collectively, the experiments shown in Figures 2 and 3 indicate that in small mesenteric resistance arteries, NO reduces agonist (U46619)-mediated vascular tone, but has no role in pressure-mediated vascular tone. However, in cirrhosis, the effect of NO on agonist (U46619)-mediated vascular tone is lost, and the effect on pressure-mediated vascular tone still remains insignificant. Previous studies 
used agonists (vasoconstrictors) to demonstrate changes in vascular tone in cirrhosis. Our data demonstrate that NO has limited role in pressure-mediated vascular tone, and there is a disparity in how NO effects agonist- vs. pressuremediated vasoconstriction.

\section{TEA has minimal effect on vascular tone in BDL- rats}

Tetraethyl ammonium (TEA, a $\mathrm{Ca}^{2+}$-activated $\mathrm{K}^{+}$ channel blocker) depolarizes vascular smooth muscle cells (VSMCs) and enhances $\mathrm{Ca}^{2+}$ influx [23]. TEA (5 $\mathrm{mM}$ ) increased vascular tone only in pressurized arteries from the SHAM-rats and had minimal effect in those from the BDL-rats (Figure 3D). Since, the large-conductance $\mathrm{Ca}^{2+}$-activated $\mathrm{K}^{+}\left(\mathrm{BK}_{\mathrm{Ca}}\right)$ channels inhibit the L-type voltage-dependent $\mathrm{Ca}^{2+}$ channels (VDCC), key channels that transports $\mathrm{Ca}^{2+}$ into VSMCs [24, 25], we assessed arterial expression of $\mathrm{BK}_{\mathrm{Ca}}$ and $\mathrm{Ca}_{\mathrm{v}} 1.2$ - the key subunit of VDCC. We observed no significant change in $\mathrm{Ca}_{\mathrm{v}} 1.2$ expression however; $\mathrm{BK}_{\mathrm{Ca}}$ expression was reduced in arteries from the BDL-rats when compared to the SHAMrats (Figures 4A-4D, 4G). These results suggested that the

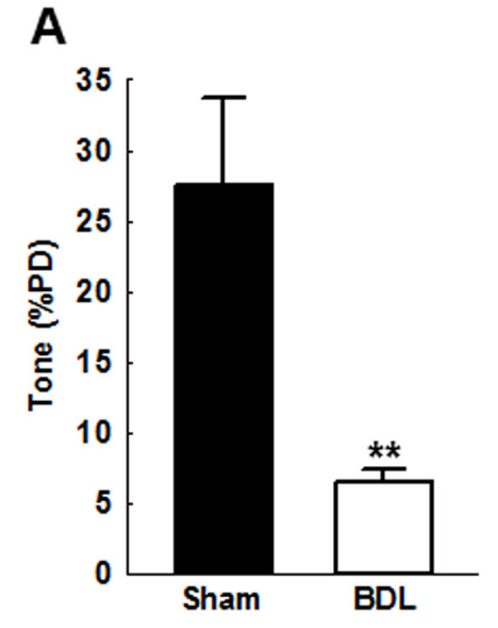

B
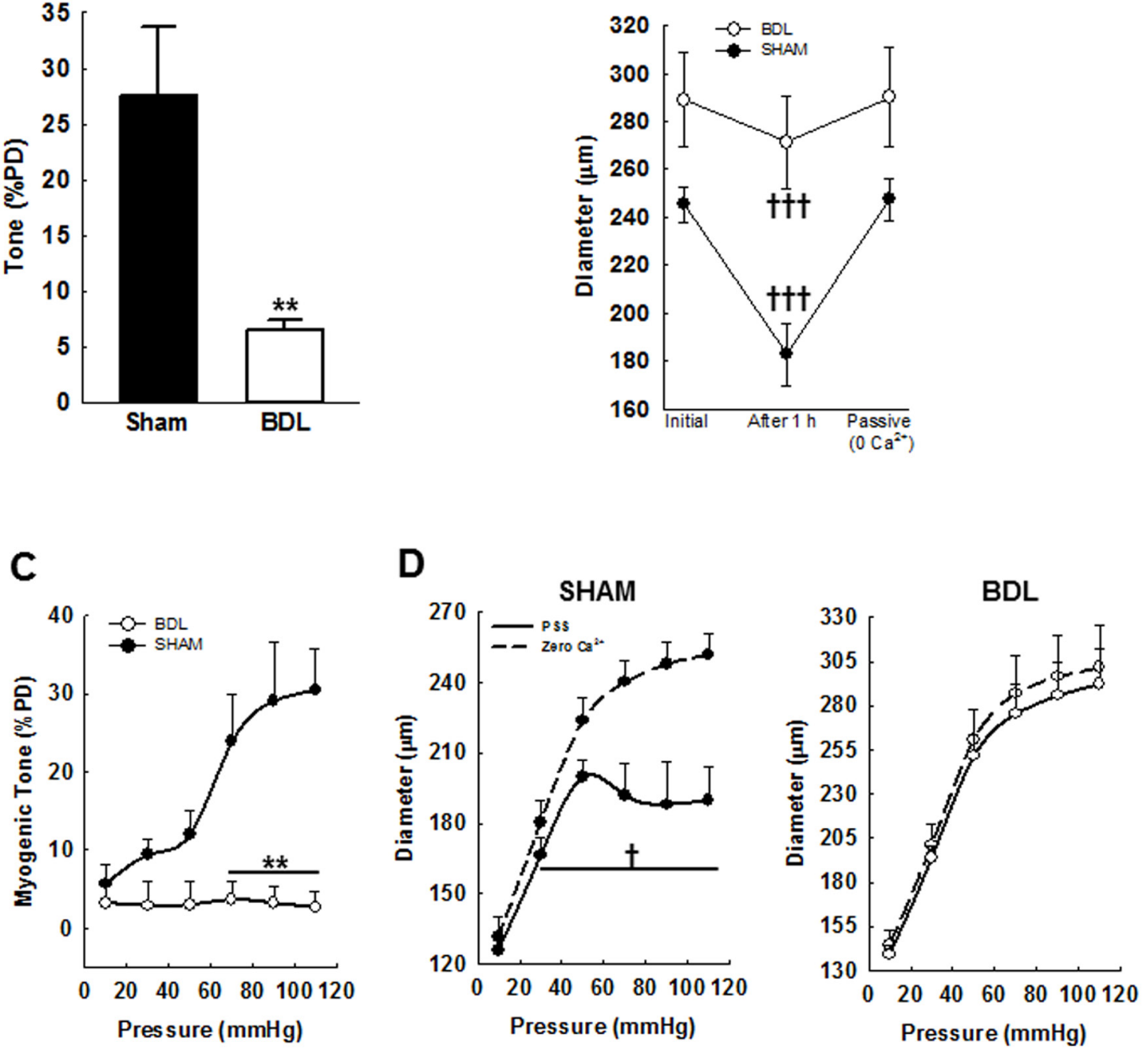

Figure 1: Effect of isobaric conditions and increasing intraluminal pressure on diameter of small mesenteric resistance arteries from SHAM- and BDL-rats. A. Compared to SHAM-rats, fourth-order mesenteric arteries from BDL-rats pressurized at $70 \mathrm{mmHg}$ and incubated with warm $\left(37^{\circ} \mathrm{C}\right)$ PSS for $1 \mathrm{~h}$ developed reduced tone. B. Change in diameters of pressurized arterial segments are shown. Passive (maximal) diameter was determined by incubating the arteries in $\mathrm{Ca}^{2+}$-free PSS. C. To determine myogenic response, intraluminal pressure was increased in steps between $10-110 \mathrm{mmHg}$ and spontaneous tone was allowed to develop until a stable diameter was achieved. The pressure-response was repeated in $\mathrm{Ca}^{2+}$-free PSS to determine the corresponding passive diameters. The myogenic tone is expressed as a percent of passive diameter (PD) and calculated as: (PD-achieved diameter) $/ \mathrm{PD} \times 100$. D. Arterial diameter at various pressure steps in PSS with and without $\mathrm{Ca}^{2+}$ are shown. ${ }^{* *} P<0.01$ when compared to SHAM-rats. $\dagger P<0.05, \dagger \dagger \uparrow P<0.001$ when compared within treatment groups ( $n=5$-6/group). 

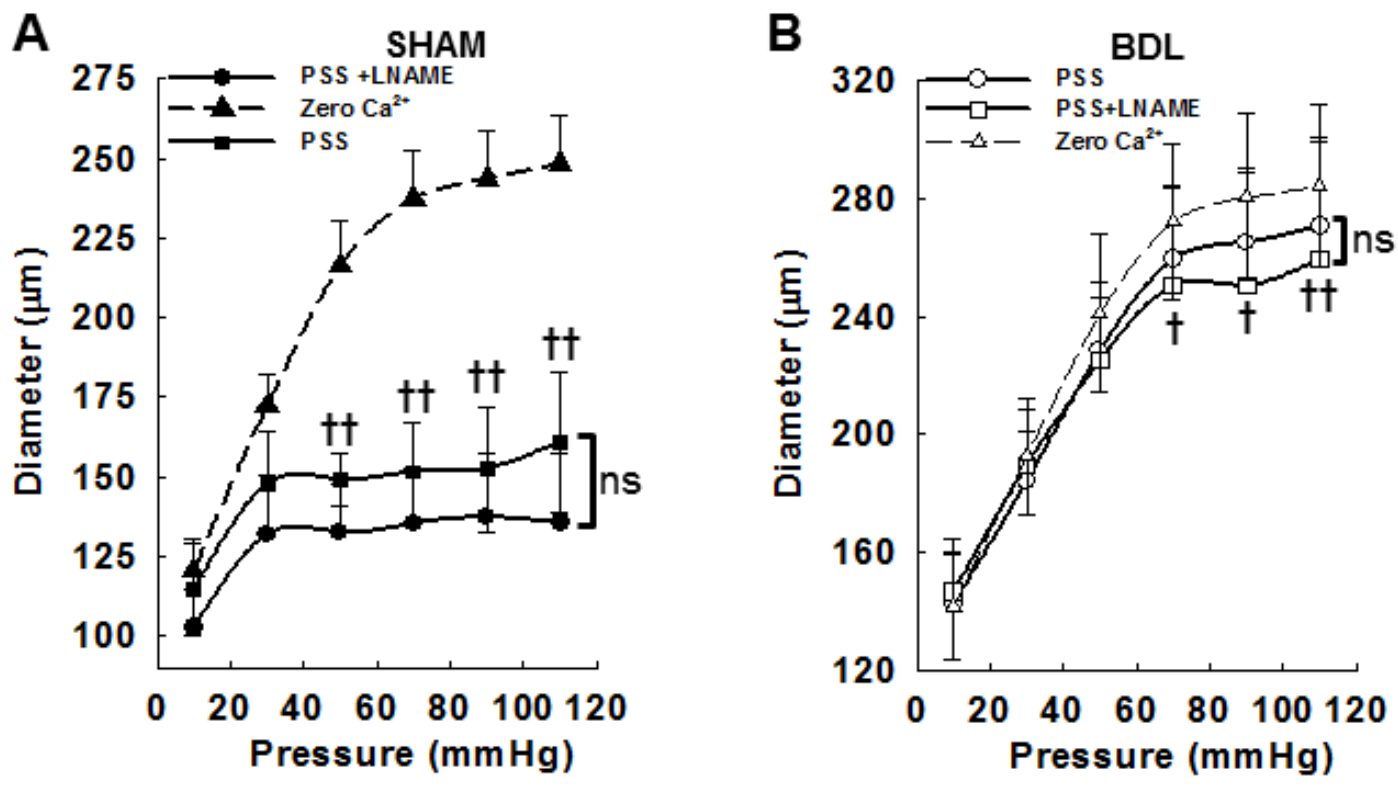

C
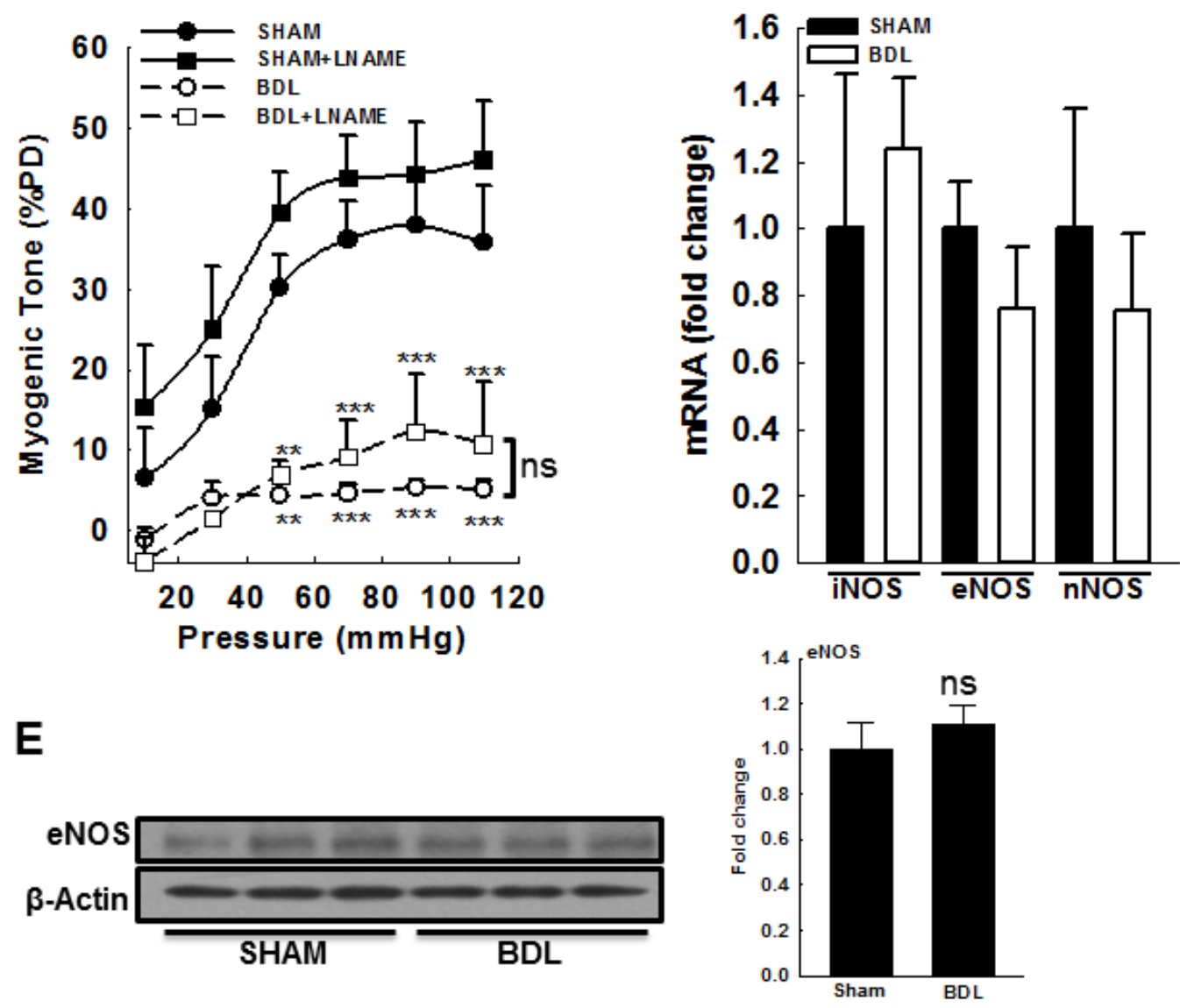

Figure 2: Effect of NOS inhibition on myogenic response in small mesenteric resistance arteries from SHAM- and BDL-rats. Arteries were subjected to a series of intraluminal pressure steps between $10-110 \mathrm{mmHg}$ before and after incubating with $300 \mu \mathrm{M}$ LNAME (a NOS inhibitor for $60 \mathrm{~min}$ ). The pressure-response was repeated in $\mathrm{Ca}^{2+}$-free PSS as described above. The arterial diameter at various pressure steps from A. SHAM-rats and B. BDL-rats are shown. C. Myogenic response was determined as described above. Incubation with LNAME improved MR minimally and non-significantly in both groups ( $n=4-6 /$ group). D. In mesenteric arteries from SHAM- and BDL-rats, the expression of mRNA for NOS isoforms was similar. E. The expression of NOS was also determined by immunoblotting; the immunoblots for eNOS and loading control are shown; The bar graph shows densitometry analysis. $* * P<0.01, * * * P$ $<0.001$ when compared to SHAM-rats. $\uparrow P<0.05$, $\dagger \uparrow P<0.01$ when compared within treatment groups; ns-not significant. 
reduced $\mathrm{BK}_{\mathrm{Ca}}$ expression, and possibly function, are the consequences of reduced vascular tone and not the cause for it. Therefore, we assessed the expression of other key channels that mediate $\mathrm{Ca}^{2+}$ influx.

\section{In BDL-rats, arterial expression of TRPC6 is reduced}

Various ion channels alter $\left[\mathrm{Ca}^{2+}\right]$ in VSMCs to modulate pressure-mediated tone. The role of such channels is being actively investigated, and their list continues to grow. Here we assessed the expression of transient receptor potential cation channels subtype 3 and 6 (TRPC3 and TRPC6), the key channels that regulate pressure-induced vasoconstriction in small resistance arteries [26, 27]. There was no significant change in TRPC3 expression (Figure 4A) however, TRPC6 expression was reduced in the arteries from BDL-rats when compared to SHAM-rats (Figures 4E-4G).

\section{In BDL-rats, mesenteric arteries have reduced sensitivity to $\mathrm{Ca}^{2+}$}

To determine if bypassing the ion channels that regulate $\mathrm{Ca}^{2+}$ influx would restore vascular tone, we used permeabilized arterial preparations. As shown in Figure $5 \mathrm{~A}$, in the permeabilized arteries pressurized at $70 \mathrm{mmHg}$, high-dose $\mathrm{Ca}^{2+}$ (pCa4.5) increased vascular tone, which remained lower in the BDL-rats when compared to the SHAM-rats; respective changes in arterial diameter are shown in Figure 5B.
A
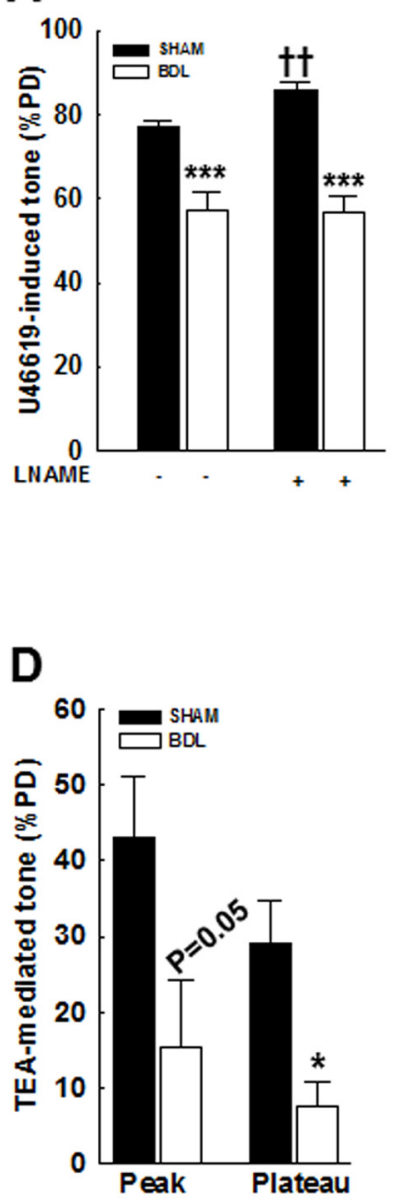

B

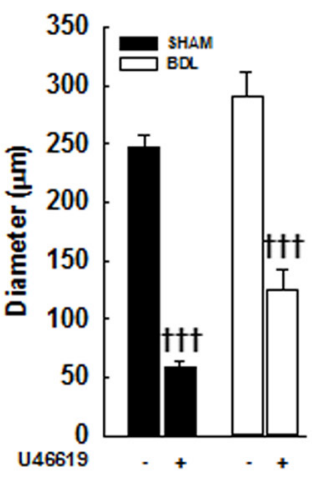

C

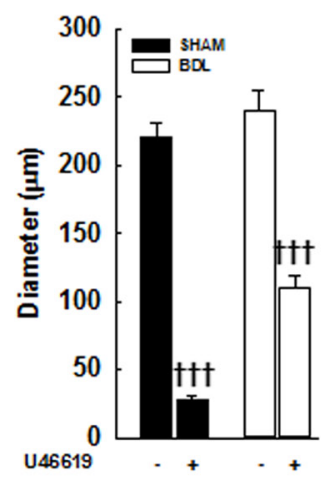

Figure 3: Effect of an agonist and TEA on vascular tone in pressurized mesenteric arteries from SHAM- and BDLrats. A. In the arteries from BDL-rats, U46619 (a thromboxane analogue and a ROCK activator)-mediated tone is reduced when compared to SHAM-rats. At $70 \mathrm{mmHg}$, arteries developed spontaneous vasoconstriction that was further augmented by $10 \mu \mathrm{M}$ U46619. Incubation with $300 \mu \mathrm{M}$ LNAME for 60 min (a NOS inhibitor) enhanced U46619-mediated vascular tone in the SHAM-rats only and had no effect in those from the BDL-rats. Arterial diameters in the B. absence and C. presence of LNAME are shown ( $n=5-6 /$ group). D. TEA (5 mM, a $\mathrm{Ca}^{2+}$-activated $\mathrm{K}^{+}$channel blocker) enhanced vascular tone in pressurized arteries from the SHAM-rats and had minimal effect on those from the BDL-rats; peak and plateau responses are shown $(n=4-6 /$ group $)$. Effect of TEA was determined in arteries incubated with LNAME. $* P<0.05, * * * P<0.001$ when compared to SHAM-rats. $\dagger \dagger P<0.01, \dagger \dagger \uparrow P<0.001$ when compared within treatment groups. 

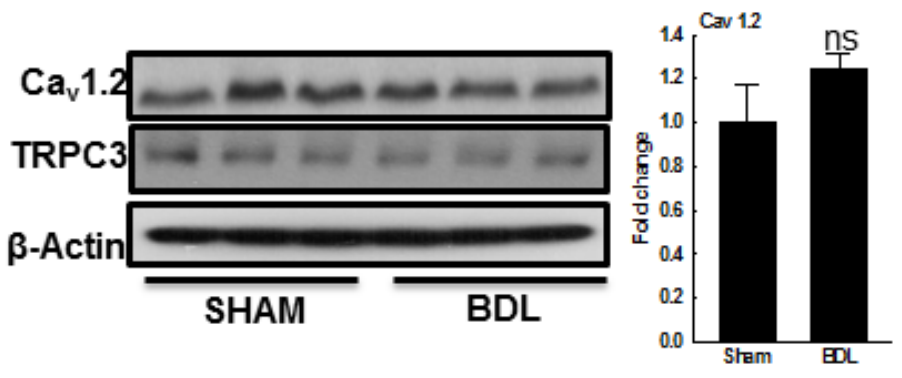
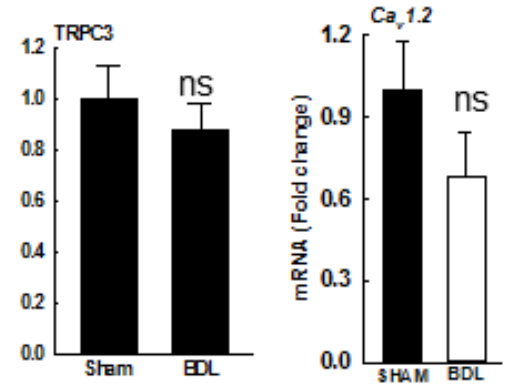

C
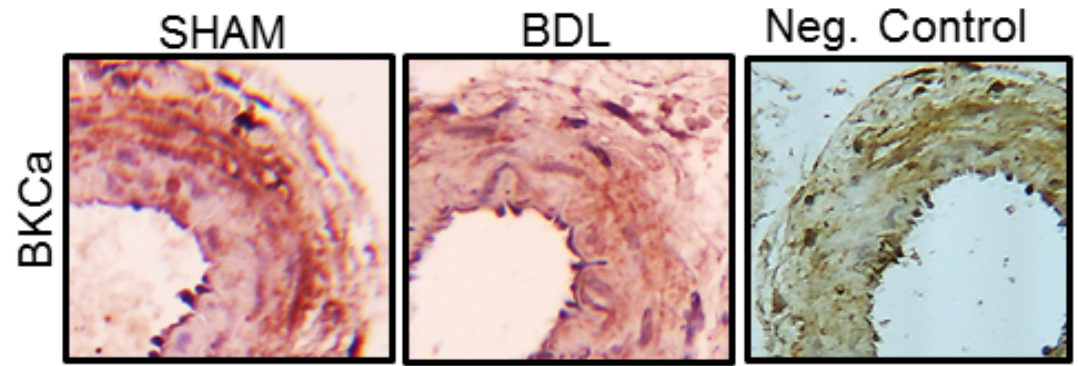

E

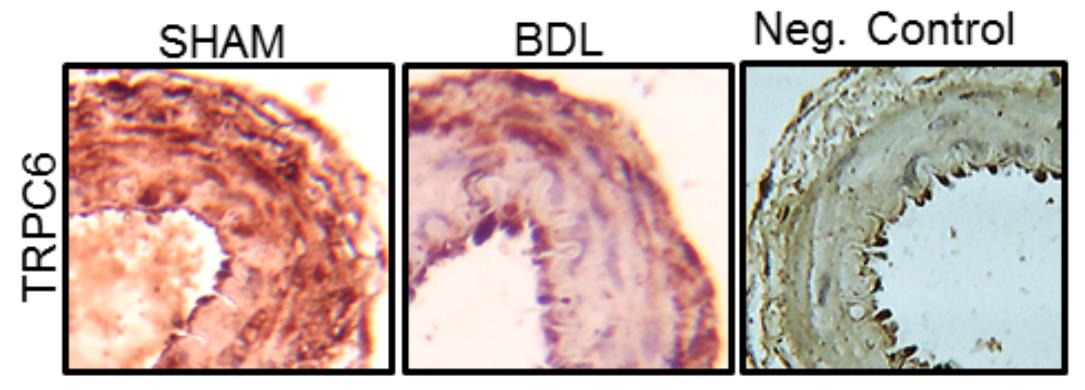

D

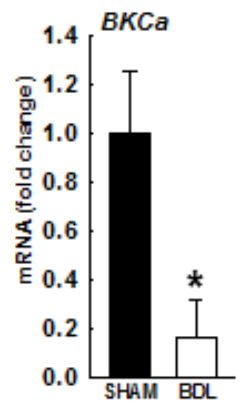

$\mathbf{F}$
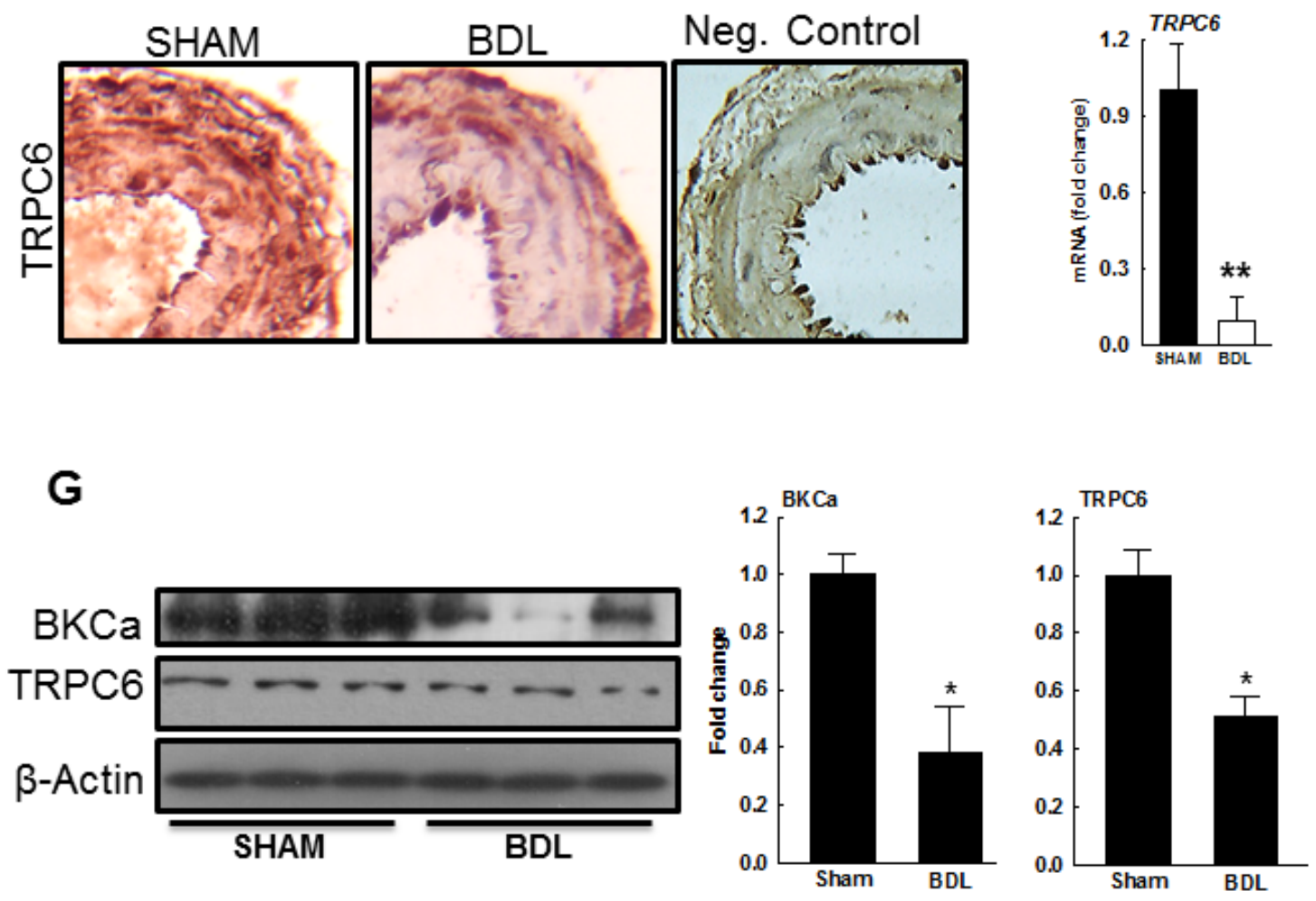

Figure 4: Expression of ion channels in small mesenteric resistance arteries from SHAM- and BDL-rats. A. Immunoblots for $\mathrm{Ca}_{\mathrm{v}} 1.2$, TRPC 3 and $\beta$-actin (loading control) from small mesenteric artery homogenates indicate no differences among both groups. The bar graphs show densitometry analyses for $\mathrm{Ca}_{\mathrm{y}} 1.2$ and TRPC3. B. qPCR for $\mathrm{Ca}_{\mathrm{v}} 1.2$. Representative IHC photographs and qPCR indicate that in the arteries from the BDL-rats, expressions of $\mathbf{C}$., D. BK ${ }_{\mathrm{Ca}}$ and E., F. TRPC6 are reduced when compared to SHAM-rats $(n=3-5 /$ group). G. The immunoblots for both $\mathrm{BK}_{\mathrm{Ca}}$ and TRPC6 and their loading controls are shown. The bar graphs show densitometry analyses for $\mathrm{BK}_{\mathrm{Ca}}$ and TRPC6 ( $n=3$ /group). $* P<0.05, * * P<0.01$ when compared to SHAM-rats. 
A

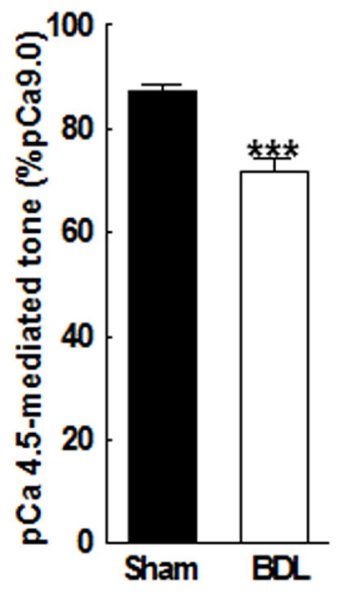

D

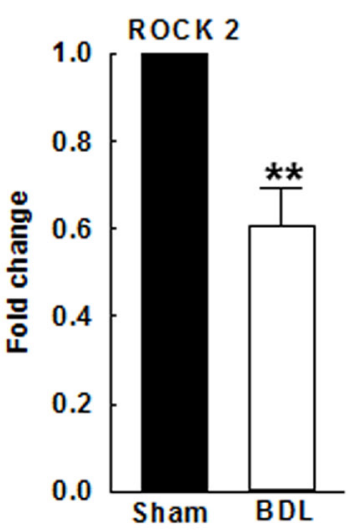

G

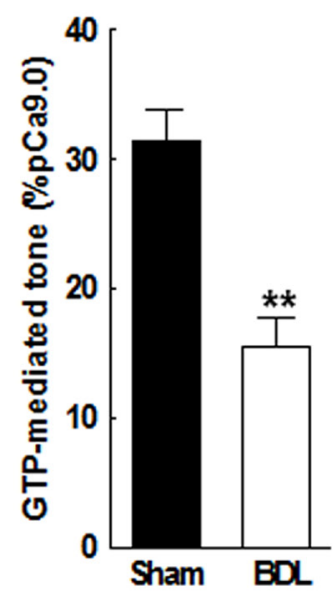

B

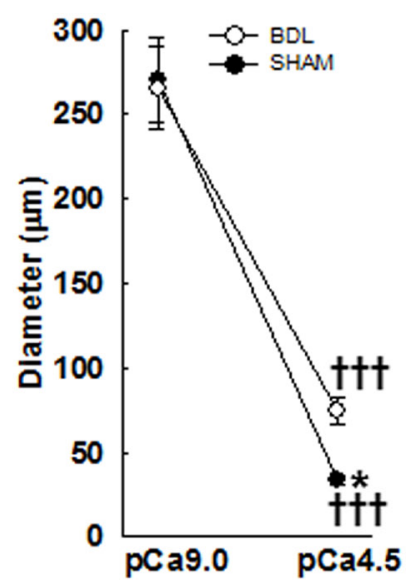

E

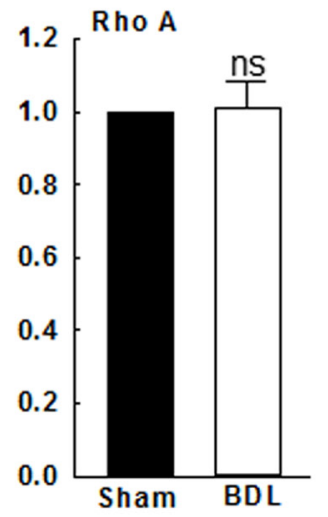

H

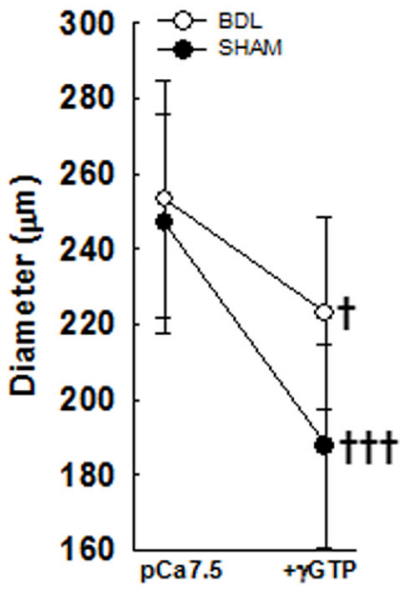

$\mathbf{F}$

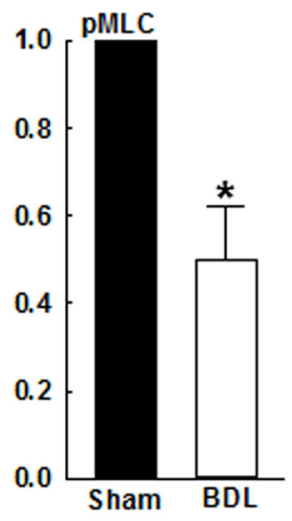

Figure 5: $\mathrm{Ca}^{2+}$ sensitivity of small mesenteric arteries from SHAM- and BDL-rats. In $\beta$-escin-permeabilized arteries pressurized at $70 \mathrm{mmHg}$, the effect of high-dose $\mathrm{Ca}^{2+}$ was assessed. A. In response to pCa4.5, vascular tone increased in all rats but remained lower in the BDL-rats compared to SHAM-rats. B. Arterial diameters at pCa9.0 and pCa4.5 are shown ( $n=4-5 /$ group). C. Immunoblots indicate reduced arterial ROCK2 and pMLC expression in the BDL-rats $(n=3 /$ group). D.-F. Summary data for ROCK2, RhoA and pMLC. G. Compared to SHAM-rats, permeabilized arteries from the BDL-rats developed reduced tone when stimulated with $100 \mu \mathrm{M} \gamma \mathrm{GTP}$ (in pCa7.5). H. Arterial diameters before and after incubation with $\gamma \mathrm{GTP}$ are shown $\left(n=4-5 /\right.$ group). ${ }^{*} P<0.05,{ }^{* *} P<0.01$, $* * * P<0.001$ when compared to SHAM-rats. $\dagger P<0.05$, $\dagger \dagger P P<0.001$ when compared within treatment groups. 


\section{In mesenteric arteries from BDL-rats, RhoA kinase pathway is inhibited}

ROCK signaling is important in regulating VSM contractility and pressure-mediated tone [21]. The RhoAmediated activation of ROCK2 regulates VSM contraction by modulating myosin light chain (MLC) phosphorylation. And, VSM contractility can be sustained or enhanced at fixed $\mathrm{Ca}^{2+}$ concentrations by increasing $\mathrm{Ca}^{2+}$ sensitivity via activation of ROCK. Therefore, in the mesenteric arteries from both groups, we evaluated the expression of RhoA, ROCK2 and phosphorylation of MLC subunit-20. Figures $5 \mathrm{C}-5 \mathrm{~F}$ indicate that arterial expressions of ROCK2 and pMLC were decreased in the BDL-rats when compared to the SHAM-rats; The RhoA expression was similar. Based on these observations, we hypothesized that impaired $\mathrm{Ca}^{2+}$ sensitivity plays a significant role in reduced pressure-induced vascular tone in cirrhosis. Therefore, to assess the functional impact of low ROCK2 expression, in pressurized permeabilized arteries we assessed the effect of GTP, which activates ROCK. $\gamma$ GTP $(100 \mu \mathrm{M})$ mediated vascular tone was attenuated in the BDL-rats when compared to the SHAM-rats (Figures $5 \mathrm{G} \& 5 \mathrm{H}$ ).

\section{In BDL-rats, arterial intraluminal cross-section area and elasticity are increased}

As shown in Figures $6 \mathrm{~A} \& 6 \mathrm{~B}$, the luminal area of arteries from the BDL-rats was more than those from the SHAM-rats. After development of MT, arterial luminal area reduced more in the SHAM-rats than in the BDLrats. However, after development of MT, there was no difference in the arterial wall thickness among both groups (Figure 6C). Collectively these data suggested that factors other than $\mathrm{Ca}^{2+}$ influx and sensitization may be at play. Therefore, we assessed for changes in arterial distension in $\mathrm{Ca}^{2+}$-free PSS. At lower intraluminal pressure (10-30 $\mathrm{mmHg}$ ), the luminal area was similar in both groups but at higher pressure $(50-110 \mathrm{mmHg})$, was significantly higher in the BDL-rats (Figure 6D). Across the entire intraluminal pressure range, the BDL-rats had increased arterial wall thickness when compared to the SHAM-rats (Figure 6E). Additionally, in the BDL-rats, stress-strain curve shifted rightward (Figure 6F). These data indicated that the arteries from BDL-rats are more elastic that those from SHAM-rats. Therefore, to investigate the causes for increased arterial elasticity in the BDL-rats, we assessed for changes in modulators of extracellular matrix (ECM). In the BDL-rats, arterial expressions of collagen 1a1 and $3 a 1$ were reduced and expression of MMP-9 increased (Figures 6G-6L). There was no change in MMP-2 expression (Figure 6J). Gelatin zymography demonstrated that in the arteries from BDL-rats, MMP-9 activity was increased when compared to SHAM-rats (Figures 7A\&B).

\section{In BDL-rats, plasma ROS levels are increased}

In cirrhosis, numerous factors, i.e., inflammatory cytokines, shear stress and ROS, are thought to mediate vascular changes. For example, in conduit arteries of cirrhotic animals, peroxynitrite adducts are increased [14, 28]. However, it's not clear if peroxynitrite generation in small resistance arteries plays a role. We assessed for peroxynitrite adducts in the arteries from both groups (by IHC and immunoblotting) however, did not observe any substantive differences (data not shown). Since exogenous peroxynitrite has been shown to reduce vascular tone in cerebral arteries [29], we hypothesized that the vascular changes observed in the BDL-rats could be due to increased circulating ROS levels. We assessed in the rat plasma, ROS levels by measuring MDA levels, and oxidation of DCFDA to DCF. Figures 7C \& 7D indicate that the BDL-rats had markedly increased circulating ROS levels compared to the SHAM-rats.

\section{In VSMCs, oxidative stress enhances MMP-9 activity and reduces ROCK2 expression}

Since the circulating ROS levels were increased in the BDL-rats, we hypothesized that ROS induce molecular changes observed in resistance mesenteric arteries. To test this hypothesis we incubated the rat VSMCs with peroxynitrite (or SIN-1) and assessed MMP-9 activity in their supernatant. Figures 7E \& 7F show that peroxynitrite (and SIN-1) enhanced MMP-9 activity in VSMC media. Finally, we assessed the effect of peroxynitrite on ROCK2 expression. We observed that rat VSMCs incubated with peroxynitrite for $24 \mathrm{~h}$, had reduced ROCK 2 expression (Figures $7 \mathrm{G} \mathrm{\&} \mathrm{7H).} \mathrm{These} \mathrm{data} \mathrm{indicated} \mathrm{that} \mathrm{in} \mathrm{cirrhosis,}$ increased circulating ROS potentially modulate arterial $\mathrm{ECM}, \mathrm{Ca}^{2+}$ sensitivity, and thus elasticity.

\section{DISCUSSION}

In early cirrhosis, increased cardiac output maintains normal blood pressure. As the cirrhosis progresses, systemic arterial vasodilation increases and SVR decreases, and increased cardiac output cannot compensate to maintain the "normal" blood pressure $[30,31]$. The progressively decreasing SVR worsens renal under-perfusion and promotes fluid retention [3]. These hemodynamic changes trigger activation of reninangiotensin system and sympathetic activity. However, despite elevated catecholamine and angiotensin levels, the arterial contractility remains attenuated [14, 32, 33]. Previous investigations identified various mechanisms likely responsible for hypocontractility of agoniststimulated conduit arteries however, changes in pressuremediated vascular tone have not been investigated. 
A

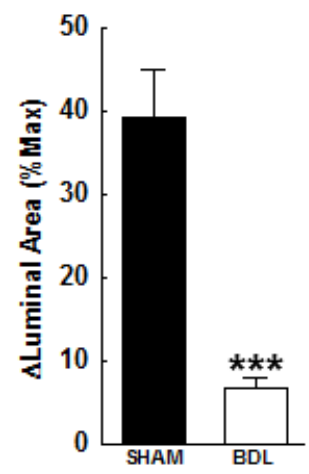

D

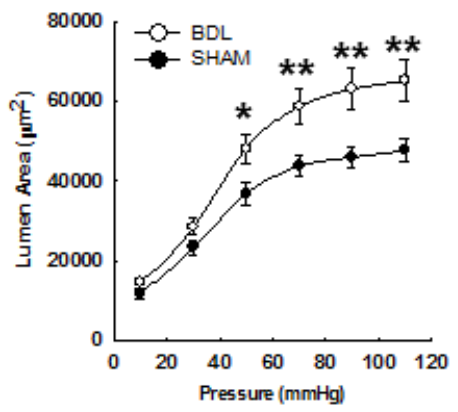

G

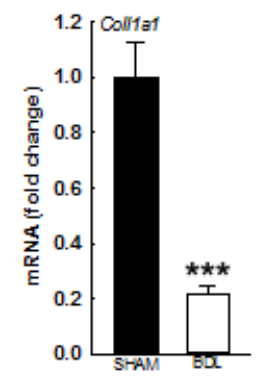

K

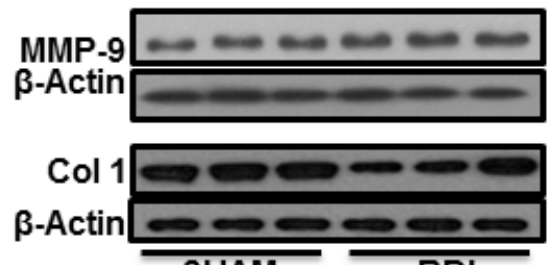

B

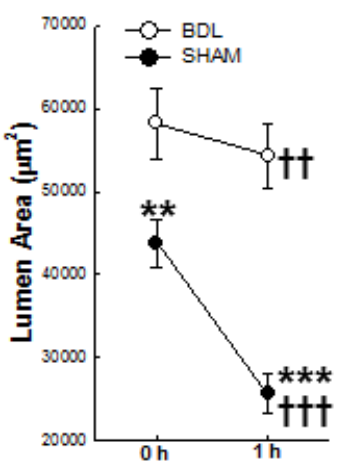

E

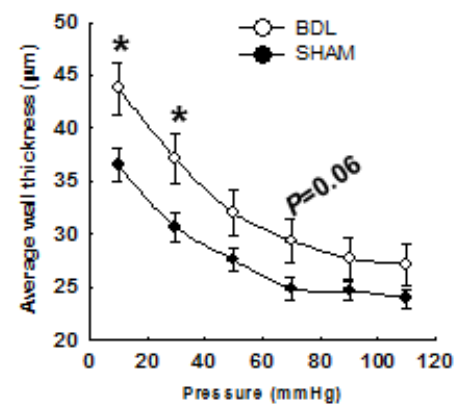

H

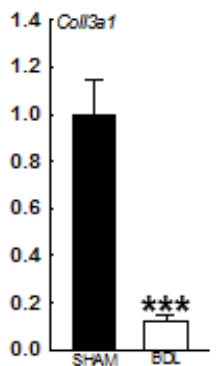

I

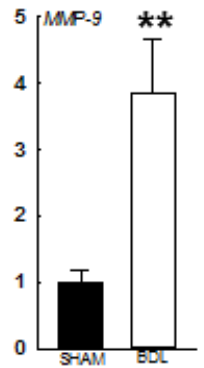

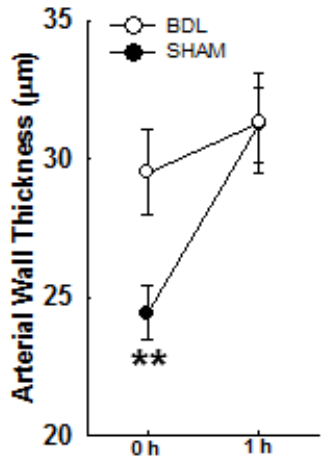

F

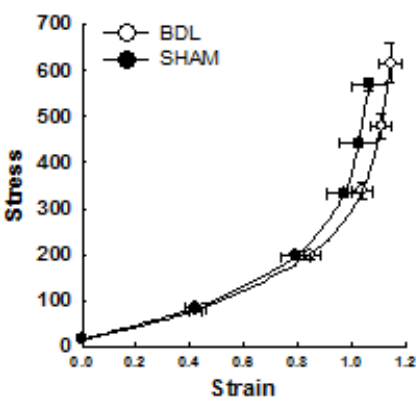

J

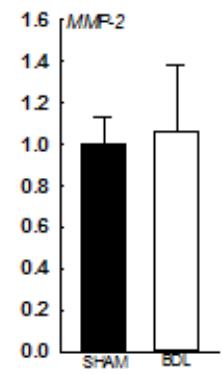

L

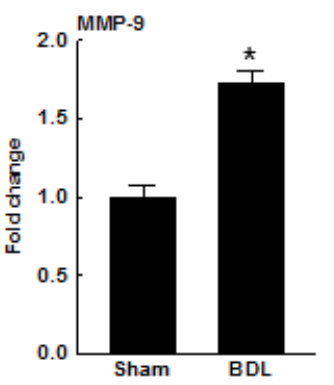

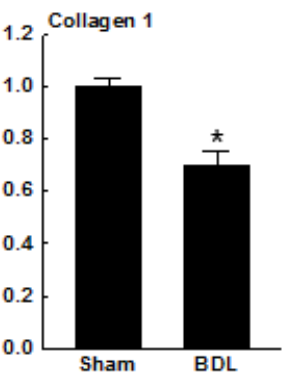

Figure 6: Effect of BDL on arterial elasticity. A. After development of MT in isobaric conditions (within $1 \mathrm{~h}$ ), the luminal area decreased in both but significantly more in the arteries from SHAM-rats than BDL-rats; B. Respective changes in luminal area. C. Arterial wall thickness was more in the BDL-rats, but after development of MT, was equal to those in the SHAM-rats $(n=16-17 /$ group). To determine the effect of pressure on passive distension, arteries were incubated in $\mathrm{Ca}^{2+}$-free PSS. D. Increasing intraluminal pressure led to enhanced arterial distension in the BDL-rats. E. Arterial wall thickness in $\mathrm{Ca}^{2+}$-free PSS across intraluminal pressure range is shown. F. In the arteries from BDL-rats, stress-strain relation curve shifted right- and up-ward ( $n=16$ /group). Arterial expression of mRNA for G. collagen 1a1, H. collagen 3a1, I. MMP-9 and J. MMP-2 are shown ( $n=5-6 /$ group). K. The immunoblots for both MMP-9, collagen 1 and their loading controls are shown. L. The bar graphs show densitometry analyses for MMP-9 and collagen $1(n=3 /$ group). $* P<0.05$, $* * P$ $<0.01, * * * P<0.001$ when compared to SHAM-rats. $\uparrow \dagger P<0.01, \dagger \dagger P<0.001$ when compared within treatment groups. 
A

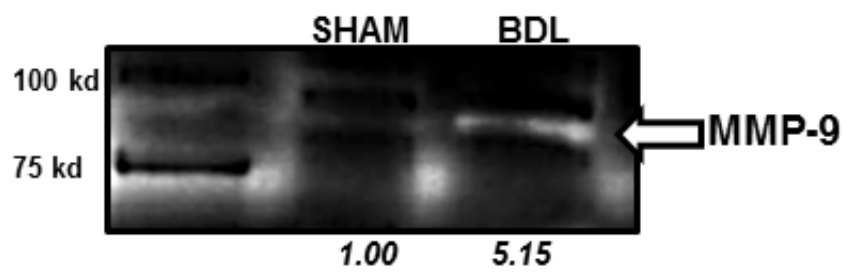

B

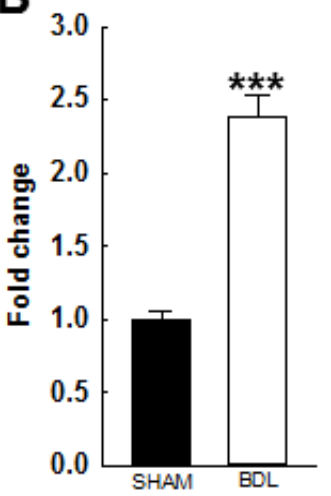

C

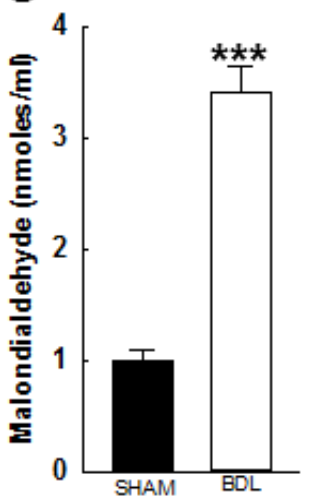

D

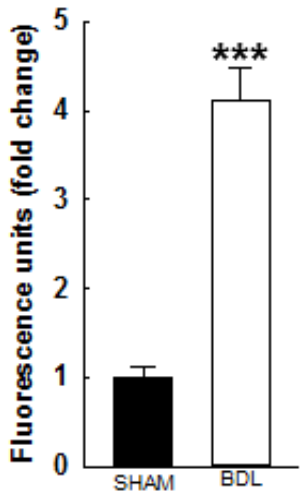

E

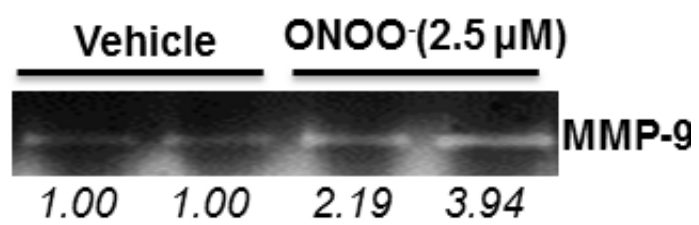

F

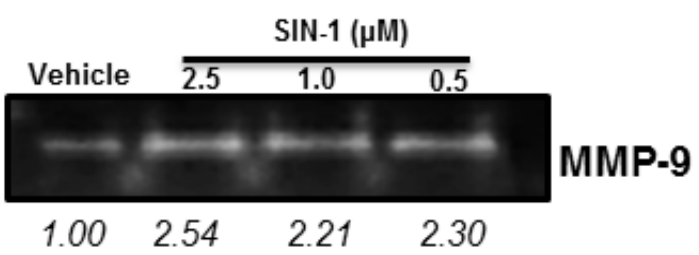

G

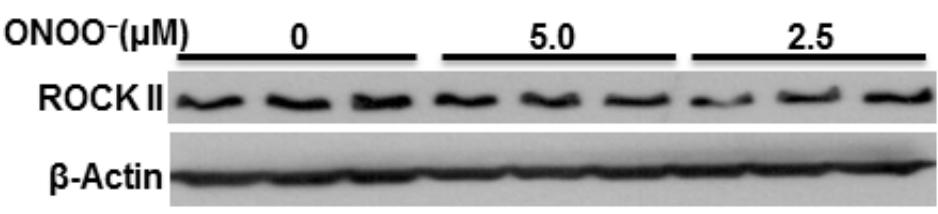

H

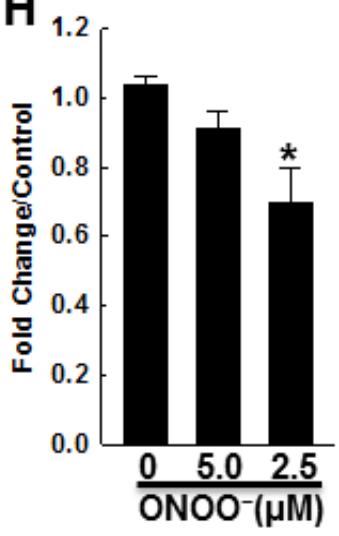

Figure 7: Effect of BDL and ROS on vascular MMP-9 activity. A. Representative gelatin zymography indicates that in arteries from BDL-rats, MMP-9 activity is increased. B. Summary data ( $n=3$ /group). Circulating ROS levels were measured in the plasma from BDL- and SHAM-rats. In BDL-rats, the plasma C. MDA levels and D. DCDF fluorescence were markedly increased when compared to SHAM-rats ( $n=4$ /group). These data indicated that in cirrhosis, systemic circulation is an ample source of oxidative stress. Representative zymography indicates that incubation of rat VSMCs with both $\mathbf{E}$. peroxynitrite and F. SIN-1 induces MMP-9 activity. G. Immunoblots and their densitometry data (I) indicate that in rat VSMCs, peroxynitrite reduces ROCK2 expression ( $n=3 /$ group). Arabic numerals indicate densitometric values. $* P<0.05$ when compared to vehicle-treated cells. $* * * P<0.001$ when compared to SHAM-rats. 
MT and MR - the phenomena observed only in small resistance arteries and not in conduit arteries [25] — are independent of neurohumoral and endothelial contribution [11, 34]. The changes in the sensitivity of conduit arteries to vasoconstrictors and vasodilators, are not sufficient to explain the hemodynamic changes in cirrhosis. Therefore, in this study, we characterized the changes in pressure-mediated vascular tone of small resistance arteries, the key site for SVR.

We observed that in small resistance arteries from BDL-rats: 1) the pressure-mediated vascular tone is markedly attenuated that is independent of $\mathrm{NO}$; 2) expression of TRPC6 is reduced; 3) expression of ROCK2 is reduced which is associated with reduced MLC phosphorylation, and responsible for attenuated GTP-mediated tone; 4) intraluminal cross-sectional area is increased that is associated with reduced expression of collagen and increased expression and activity of MMP-9; 5) circulating levels of ROS are augmented; and finally, in VSMCs, oxidative stress induces MMP-9 activity and reduces ROCK2 expression.

Endothelium-derived NO plays an important role in vascular reactivity by diffusing into VSMCs and reducing $\mathrm{Ca}^{2+}$ influx, thereby reducing vascular tone [35, 36]. Some studies showed that in conduit arteries from cirrhotic animals, acetylcholine-mediated vasodilation was augmented due to increase NO release; However, others suggested that NO's contribution was limited $[14,28]$. We evaluated the role of NO by assessing for pressure-mediated vasoconstriction in the presence of a NOS inhibitor (LNAME). LNAME failed to correct MR in arteries from BDL-rats, or enhance MR in the arteries from SHAM-rats. Lack of change in expression of NOS isoforms corroborated our functional studies. Since the circulatory NO levels are elevated in cirrhosis [37], it is possible that increased NO produced in the conduit arteries may still circulate downstream to modulate vascular tone in the small resistance arteries.

The ion channels in VSMCs play major role in modulating pressure-mediated vascular tone [38].We assessed the expression of $\mathrm{BK}_{\mathrm{Ca}}, \mathrm{Ca}_{\mathrm{v}} 1.2$, and TRPC3\&6 in the arteries from BDL- and SHAM-rats. The arterial expression of TPRC3 and $\mathrm{Ca}_{\mathrm{v}} 1.2$ were not altered, while TRPC6 expression was significantly reduced in the BDL-rats. Since TRPC6 plays an important role in regulating pressure-mediated tone in resistant arteries [39], the observed reduction in vascular tone BDL-rats can be partially due to reduced expression of TRPC6. Concomitantly, $\mathrm{BK}_{\mathrm{Ca}}$ expression was reduced in the arteries from BDL-rats. Since, $\mathrm{BK}_{\mathrm{Ca}}$ inhibits VDCC, reduced expression of $\mathrm{BK}_{\mathrm{Ca}}$ is expected to enhance pressure-mediated vascular tone. Interestingly, others also reported reduced expression of $\mathrm{Ca}^{2+}$-activated $\mathrm{K}^{+}$ channels in conduit arteries from cirrhotic rats [28]. Therefore, the reduced TEA response in the BDL-rats (Figure 4D) suggests that the reduced $\mathrm{BK}_{\mathrm{Ca}}$ expression is an adaptive consequence to reduced MT and MR. TEA is a non-selective $\mathrm{K}_{\mathrm{Ca}}$ channel blocker. In addition to $\mathrm{BK}_{\mathrm{Ca}}$, it can also block other $\mathrm{K}_{\mathrm{Ca}}$ channels. Moreover, various other $\mathrm{K}$ channels such as $\mathrm{K}_{\mathrm{IR}}, \mathrm{K}_{\mathrm{ATP}}$, and $\mathrm{K}_{\mathrm{V}}$ which are also expressed in vasculature, can modulate vascular tone. In fact, there has been a suggestion that increased $\mathrm{K}_{\mathrm{ATP}}$ gating may play role in reducing tone [40]. However, this was reported in VSMC from superior mesenteric arteries and not the resistance arteries. Therefore, in cirrhosis, further investigation is needed to assess the role of various $\mathrm{K}$ channels in regulation of vascular tone in resistance arteries.

Based on varied expression of ion channels, we hypothesized that bypassing them would restore pressure-mediated vascular tone in BDL-rats. To test this hypothesis, we used permeabilized arteries to achieve desired intracellular $\mathrm{Ca}^{2+}$ levels $[41,42]$. High-dose $\mathrm{Ca}^{2+}$ enhanced vascular tone, which remained lower in BDLrats. In conduit arteries from cirrhotic rats, expression of $\mathrm{Ca}^{2+}$ sensitization proteins is reduced which may be responsible for reduced agonist-induced constriction [8]. We observed that in arteries from BDL-rats, expression of ROCK2 was reduced. Reduced vasoconstriction in BDLrats to stimulation by U46619, which activates ROCK pathway in VSMC [21, 43], also suggested reduced ROCK signaling $[22,44]$. Importantly, attenuated vascular tone in response to exogenous GTP indicated that reduced expression of ROCK2 is functionally responsible for reduced pressure-mediated vascular tone in BDL-rats.

Resch and Wiest et al., suggested that the small mesenteric resistance arteries undergo remodeling that results in increased elasticity [45]. They observed in cirrhotic rats, an increase in luminal cross-sectional area and structural changes in elastic lamina but no change in ECM or vascular smooth muscle. We observed that in $\mathrm{Ca}^{2+}$-free PSS, the arteries from BDL-rats had increased wall thickness (Figure 7E), though in PSS with $\mathrm{Ca}^{2+}$ at $70 \mathrm{mmHg}$, they achieved similar thickness as SHAMrats (Figure 7C). However, in both PSS with or without $\mathrm{Ca}^{2+}$, the cross-sectional area of arteries from BDL-rats remained higher. These data suggested that in BDL-rats, additional non-VSM factors are responsible for reduced vascular tone. Collagen is a known substrate of MMP-9 [46]. Reduced collagen expression, and increased MMP-9 expression and activity explain increased arterial elasticity in the BDL-rats as in $\mathrm{Ca}^{2+}$-free PSS, arteries from BDLrats compared to those from SHAM-rats had increased distension (passive diameter) across all intraluminal pressures. Our findings match those of Resch and Wiest et al., but they are in contrast to those by Fernández-Varo et al [47], who reported a decrease in arterial wall thickness, increased collagen expression and reduced MMP-9 expression and activity in cirrhotic rats. These differences are potentially due to dissimilarities in mode of induction of cirrhosis (BDL vs. $\mathrm{CCL}_{4}+$ phenobarbital), arterial beds studied (resistance vs. conduit), and techniques used to 
measure arterial wall thickness (pressurized ex vivo vs. fixed).

Others have shown increased peroxynitrite staining in conduit arteries from cirrhotic rats [14, 28], however, in small resistance arteries we could not replicate these results (not shown). We measured ROS levels in systemic circulation from BDL- and SHAM-rats, and their role in MMP-9 activity. Our findings indicate that circulatory ROS levels are markedly increased in BDL-rats, and in VSMCs in vitro, ROS increased MMP-9 activity and reduced ROCK2 expression (Figure 7). These data indicated that systemic circulation is a source of stimuli that reduces arterial tone by possibly ECM remodeling and reducing $\mathrm{Ca}^{2+}$ sensitivity.

Our study has a few limitations. Despite decrease in TRPC6 expression, we did not measure associated decrease in $\mathrm{Ca}^{2+}$ influx. The techniques and instruments required to simultaneously measure changes in MT and $\mathrm{Ca}^{2+}$ influx in small arteries are highly challenging and not commonly available. Additionally, the role of $\mathrm{BK}_{\mathrm{Ca}}$ in MT in cirrhosis will require additional in-depth investigation. And while we observed changes in ROCK2 expression, we did not assess the expression of other $\mathrm{Ca}^{2+}$ sensitizers such as PKC. Despite these limitations our data comprehensively demonstrate that in cirrhosis, multiple adaptations are responsible for reduced vascular tone, and targeting only one component such as enhancing $\mathrm{Ca}^{2+}$ influx, or modulating ROCK2 expression may not be sufficient to reverse them.

While other investigators assessed the changes in vascular tone and structural changes in superior mesenteric artery and mesenteric artery respectively in cirrhotic and portal hypertensive rats, our study provides additional insights into the mechanisms underlying changes in vascular tone, which are as follows: 1) We conducted all the experiments in pressurized small mesenteric arteries that developed spontaneous vasoconstriction, which is the most relevant physiological model; 2) We have demonstrated for the first time that in cirrhosis, pressuremediated vascular tone is reduced. None of the previous studies investigated the changes in pressure-mediated vascular tone, the key contributor of SVR; 3) Our data indicate that reduction in pressure-mediated vascular tone is multifactorial i.e., changes in expression and function of MMP-9, TRPC, and ROCK2; 4) By demonstrating that GTP-mediated tone is reduced in the small-mesenteric arteries, we showed that reduced ROCK2 expression is functionally responsible for reduced vascular tone in cirrhosis; 5) Our data suggest that circulating ROS may be responsible for regulating the expression of MMP-9 and ROCK in small mesenteric arteries, which in turn reduce pressure-mediated vascular tone; 6) Finally, we provided a proof-of-concept in vitro that in vascular smooth muscle cells, oxidative stress can reduce ROCK2 expression and enhance the MMP-9 activity. These novel findings enhance our insight into the mechanisms underlying reduced SVR in cirrhosis.
Repeated liver injury as seen in alcohol abuse, fatty liver diseases or chronic viral hepatitis leads to generation of ROS within hepatic parenchyma that promotes hepatocyte apoptosis, activates stellate cells (the hepatic fibroblasts) and plays a significant role in the development of fibrosis and cirrhosis. In animal models, treatment with anti-oxidants reduces chronic liver injury. Previously, investigators showed that treatment of BDLrats with an anti-oxidant improves vascular dynamics [48]. However, and very importantly, it is not clear if such an improvement is due to a direct effect on vasculature, or a consequence of improvement in liver injury and fibrosis [28]. Here we propose that in cirrhosis, circulating ROS are likely responsible for the vascular dysfunction of small resistance arteries by inducing oxidative stress. Therefore, in future, novel anti-oxidant molecules that are effective on vasculature alone and not the liver, or can be exclusively applied to the resistance arteries without absorption in the liver, will be crucial in answering this question.

\section{MATERIALS AND METHODS}

\section{Bile duct ligation}

All animal experiments were performed according to the Guide for Care and Use of Laboratory Animals prepared by the United States National Academy of Sciences (National Institutes of Health) and approved by the Institutional Animal Care and Use Committee. Male Sprague-Dawley rats ( $250 \mathrm{~g}$, Harlan Laboratories, USA) were housed under identical conditions in a pathogenfree environment with a 12:12 h light: dark cycle and had free access to laboratory chow and water. Rats were acclimatized for a week before the surgery. BDL was performed as described earlier [49]. Briefly, rats were anesthetized with ketamine $(100 \mathrm{mg} / \mathrm{kg}$ i.p. $)$ and xylazine (4 $\mathrm{mg} / \mathrm{kg}$ i.p. ), a laparotomy performed, the bile duct isolated, doubly ligated with a 5-0 silk suture, and resected between two ligatures. The abdominal wall was closed with a 4-0 PGA suture and the skin with a 4-0 nylon suture (all sutures; AD Surgical, Sunnyvale, CA). The control animals (SHAM) underwent laparotomy, isolation of bile duct that was not ligated, and abdominal wall closure. Animals were weighed weekly. Approximately 4 weeks after the surgery, all animals were euthanized. Their blood and livers were collected and stored, and mesenteric arteries harvested.

\section{Solutions}

All reagents were purchased from Sigma-Aldrich (St. Louis, MO) unless indicated. Dissection solution (mM/L): 3.0 MOPS, $145.0 \mathrm{NaCl}, 5.0 \mathrm{KCl}, 2.5 \mathrm{CaCl}_{2}, 1.0$ $\mathrm{MgSO}_{4}, 1.0 \mathrm{KH}_{2} \mathrm{PO}_{4}, 0.02$ EDTA, 2.0 sodium pyruvate 
Table 1: primer sequences.

\begin{tabular}{|c|c|c|}
\hline \multirow{2}{*}{ Gene } & \multicolumn{2}{|c|}{ Primer sequences } \\
\cline { 2 - 3 } & Forward & Reverse \\
\hline BKCa & TCAGCATTGGTGCCCTTGTA & CTGCAATAAACCGCAAGCCA \\
\hline Cav1.2 & ATGAGCATGCCCACAAGTGA & AGTAGCGGCTGAACTTGGAT \\
\hline eNOS & GGCTGAGTACCCAAGCTGAG & ATTGTGGCTCGGGTGGATTT \\
\hline Gapdh & TCTCTGCTCCTCCCTGTTCTA & TACGGCCAAATCCGTTCACA \\
\hline iNOS & TGTTAGCCTAGTCAACTACAAGC & GTTGTTGGGCTGGGAATAG \\
\hline nNOS & AAGGTCCGATTCAACAGCGT & CCGAACACTGAGAACCTCACA \\
\hline TRPC6 & TATCTGCTGATGGACGAGCTG & GTTTTCATTACCCCGGAAGCTG \\
\hline
\end{tabular}

and 5.0 glucose $(\mathrm{pH}$ 7.4). Physiological salt saline (PSS; mM/L): $112.0 \mathrm{NaCl}, 25.7 \mathrm{NaHCO}_{3}, 4.9 \mathrm{KCl}, 2.0$ $\mathrm{CaCl}_{2}, 1.2 \mathrm{MgSO}_{4}, 1.2 \mathrm{KHPO}_{4}, 11.5$ glucose and 10.0 HEPES. High relaxing (HR) solution (pCa9.0) in $\mathrm{mM}$ : $53.28 \mathrm{KCl}, 6.81 \mathrm{MgCl}_{2}, 0.025 \mathrm{CaCl}_{2}, 10.0$ EGTA, 5.4 $\mathrm{Na}_{2} \mathrm{ATP}$, and 12.0 creatine phosphate. The composition of pCa4.5 solution was similar to HR, except the following $(\mathrm{mM} / \mathrm{L}): 33.74 \mathrm{KCl}, 6.48 \mathrm{MgCl}_{2}$, and $9.96 \mathrm{CaCl}_{2} \cdot\left[\mathrm{Ca}^{2+}\right]$ were achieved by mixing different volumes of $\mathrm{HR}$ and pCa4.5 solutions. The permeabilization solution contained protease inhibitors leupeptin $(1 \mu \mathrm{g} / \mathrm{ml})$, pepstatin A $(2.5$ $\mu \mathrm{g} / \mathrm{ml})$, and phenylmethanesulfonylfluoride $(50 \mu \mathrm{M})$.

\section{Pressure myography}

Fourth-order mesenteric arteries parallel to the small intestine were dissected. Three-five $\mathrm{mm}$ arterial segments were transferred to a perfusion chamber, cannulated and pressurized as described previously $[12,13]$. The chamber was transferred to an inverted microscope (Motic AE31, Canada), and superfused with warm PSS (2 $\mathrm{ml} / \mathrm{min}, 37^{\circ} \mathrm{C}, \mathrm{pH} 7.4$, equilibrated with gas mixture: $5 \%$ $\mathrm{CO}_{2}, 5 \% \mathrm{O}_{2}$ and $90 \% \mathrm{~N}$ ). The intraluminal pressure was increased to $100 \mathrm{mmHg}$, and segments with leaks were discarded. Subsequently, arterial segments were allowed to equilibrate at $70 \mathrm{mmHg}$ [12]. The arteries were viewed with a 10X objective equipped with a monochrome video charge-coupled device camera, and their luminal diameter recorded continuously by image capture with a video frame grabber and real-time edge-detection system (Ionoptix, Milton, MA). At the end of each experiment, passive diameter (PD, i.e., maximal diameter) was determined by incubating the arteries in $\mathrm{Ca}^{2+}$-free PSS for $20 \mathrm{~min}$. All experiments were performed at $70 \mathrm{mmHg}$ unless indicated.

\section{Myogenic response}

The arteries were subjected to incremental pressures between 10 and $110 \mathrm{mmHg}(10,30,50,70,90$ and 110), and at each pressure-step, diameter was allowed to stabilize for $5 \mathrm{~min}$. Subsequently, the pressure-response curve was repeated in $\mathrm{Ca}^{2+}$-free PSS (containing $3 \mathrm{mM}$ EGTA and $0.01 \mathrm{mM}$ diltiazem). For each pressure-step, MT was calculated as the percent difference in diameter with and without $\mathrm{Ca}^{2+}$ containing PSS [12].

The intraluminal cross sectional area was calculated as $\pi r^{2}$. The circumferential stress was calculated as: $(\mathrm{P} d \mathrm{i}) /$ $(2 M)$ where $\mathrm{P}$ was intraluminal pressure $(\mathrm{mmHg}), d \mathrm{i}$ lumen diameter $(\mu \mathrm{m})$, and $M$ wall thickness $(\mu \mathrm{m})$. The circumferential strain was calculated as: $\left(d-d_{10}\right) / d_{10}$ where $d$ was stable lumen diameter at an intraluminal pressurestep, and $d_{10}$ was diameter at $10 \mathrm{mmHg}$.

\section{Arterial permeabilization}

The arteries were incubated in $50 \mu \mathrm{M} \beta$-escin in HR solution [41, 50-52]. After $1 \mathrm{~h}$, the arteries were washed with HR solution and pressurized at $70 \mathrm{mmHg}$. $\mathrm{Ca}^{2+}$ sensitivity was assessed by superfusing the permeabilized arteries with solutions of varied $\left[\mathrm{Ca}^{2+}\right]$ (pCa9.0, 4.5 or 7.5).

\section{Quantitative PCR (qPCR)}

The mesenteric arterial RNA was extracted using RNeasy Mini Kit (Qiagen, Valencia, CA). cDNA was prepared from $0.5 \mu \mathrm{g}$ total RNA/reaction using iScript cDNA synthesis kit (Bio-Rad, Hercules, CA) and diluted with the nuclease-free water. $25 \mu 1$ reaction volume comprised $12.5 \mu \mathrm{l}$ Quantifast SYBR green master $\operatorname{mix}(2 \mathrm{X}), 1 \mu \mathrm{l}$ cDNA $(25 \mathrm{ng}), 1 \mu \mathrm{l}$ primer $(10 \mathrm{pmol} / \mu \mathrm{l}$ 
each), and $9.5 \mu$ l nuclease-free water. A two-step thermal cycling profile was used for amplification (StepOnePlus Real-Time PCR System, Applied Biosystems, Life Technologies, Grand Island, NY). Step I (cycling): $95^{\circ} \mathrm{C}$ for $5 \mathrm{~min}, 95^{\circ} \mathrm{C}$ for $10 \mathrm{~s}$ and $60^{\circ} \mathrm{C}$ for $30 \mathrm{~s}$ for 40 cycles. Step II (melting curve): $60{ }^{\circ} \mathrm{C}$ for $15 \mathrm{~s}, 60{ }^{\circ} \mathrm{C} 1 \mathrm{~min}$ and $95^{\circ} \mathrm{C}$ for $30 \mathrm{~s}$. The specific template amplification was confirmed by melting curve analysis. mRNA fold change was calculated using $\triangle \triangle C T$ method by normalizing data with housekeeping (GAPDH) gene expression. Respective forward and reverse primer sequences for target genes are shown in Table 1.

\section{Immunoblotting}

Four-to-five snap-frozen arterial segments from same animal were homogenized in RIPA lysis buffer (containing protease and phosphatase inhibitors), kept on ice for $2 \mathrm{~h}$, then centrifuged at $22000 \mathrm{~g}$ for $20 \mathrm{~min}$ $\left(4^{\circ} \mathrm{C}\right)$. The supernatant was collected and protein concentration determined using Bradford assay (SigmaAldrich, St. Louis, MO). Equivalent protein content was electrophoresed in polyacrylamide gels and transferred onto polyvinylidene-fluoride membranes. The membranes were probed with primary antibodies to ROCK2, RhoA, pMLC, MLC, (all 1:1000, Cell Signaling, Danvers, MA), MMP9 (1:1000, Santa Cruz Biotechnology, Dallas, TX), eNOS (1:1000, BD Bioscience, San Jose, CA), Collagen-1 (1:500, Southern Biotech, Birmingham, AL), Ca 1.2 , $\mathrm{BK}_{\mathrm{Ca}}$, TRPC6 and TRPC3 (all 1:500, Alomone Labs, Israel) overnight at $4^{\circ} \mathrm{C}$, followed by anti-rabbit $(1: 3000$, Cell Signaling) or anti-goat (1:3000, Sigma Aldrich, St. Louis, MO) IgG-HRP secondary antibodies. The blots were developed using Clarity Western ECL Substrate (BioRad, Hercules, CA) and autoradiography films (Genesee Scientific, San Diego, CA). The membranes were stripped using a tris-buffered solution with $2 \%$ sodium dodecyl sulfate and $100 \mathrm{mM} \beta$-mercaptoethanol at $50^{\circ} \mathrm{C}$, and reprobed with different antibodies. Band intensities were quantified by NIH Image J (http://imagej.nih.gov/ij/) and normalized to $\beta$-actin. All original blots are provided in the supplementary file.

\section{Histology and immunostaining}

The paraffin-embedded arterial sections were deparaffinized with xylene, and rehydrated with series of ethanol gradient. Following antigen retrieval (using citric acid buffer), the sections were incubated in $2 \% \mathrm{H}_{2} \mathrm{O}_{2}$ for 30 min to block endogenous peroxidase activity. To block non-specific protein binding, sections were washed with PBS and treated with $1 \%$ BSA $(60 \mathrm{~min})$ and $5 \%$ goat serum $(30 \mathrm{~min})$. Then, the sections were incubated with anti-TRPC6 or anti-BK ${ }_{\mathrm{Ca}}$ polyclonal antibodies $(1: 200$, Alomone Labs, Israel) overnight at $4^{\circ} \mathrm{C}$ in a humidified chamber. The following day, the sections were washed with PBS and incubated with biotinylated goat antirabbit $\operatorname{IgG}(\mathrm{H}+\mathrm{L})$ secondary antibody for $60 \mathrm{~min}$ at room temperature. The avidin-biotin reaction was carried out using VECTASTAIN Elite ABC kit (Vector Laboratories, Burlingame, CA) and the sections were treated with diaminobenzidine (Vector Labs). The negative controls were processed similarly but without incubation in primary antibodies. Finally, the sections were counterstained with hematoxylin, mounted using DPX, and examined under a microscope.

\section{Cell culture}

The SV40LT-transfected rat VSM cells (VSMCs, ATCC, USA) were grown in DMEM containing 10\% FBS and antibiotics, and sub-cultured using $0.25 \%(\mathrm{w} / \mathrm{v})$ Trypsin-0.53mM EDTA solution.

\section{Zymography}

Gelatin zymography was performed as described previously [53]. VSMCs $\left(1.0 \times 10^{6}\right)$ were treated with peroxynitrite $(2.5 \mu \mathrm{M})$ or its vehicle $\mathrm{NaOH}(0.5 \mathrm{mM})$, and SIN-1 $(2.5 \mu \mathrm{M})$ or its vehicle DMSO $(0.05 \%)$ in serum-free DMEM. After $24 \mathrm{~h}, 500 \mu \mathrm{l}$ culture media was collected, concentrated using Amico Ultra $0.5 \mathrm{ml}$ centrifugal filters (Merck Millipore, Billerica, MA), loaded $(7.5 \mu \mathrm{l} /$ well) onto $8 \%$ SDS-polyacrylamidegelatin gels and analyzed for MMP-9 activity. Similarly, equivalent amount of arterial protein (30 $\mu \mathrm{g})$ was electrophoresed under non-reducing conditions. The gels were washed with $2.5 \%$ Triton X-100 for 45 min, placed for $48 \mathrm{~h}$ in incubation buffer $(50 \mathrm{mM}$ Tris- $\mathrm{HCl}, 150 \mathrm{mM}$ $\mathrm{NaCl}, 5 \mathrm{mM} \mathrm{CaCl}_{2}$, and $0.05 \% \mathrm{NaN}_{3}$ ) at $37^{\circ} \mathrm{C}$, stained with $0.05 \%$ Coomassie Brilliant Blue, and then de-stained until enzyme activity was detected as colorless bands and photographed in a gel documentation system (Bio-Rad, Hercules, CA, USA). Band intensities were quantified by NIH Image J (http://imagej.nih.gov/ij/). A protein ladder (Bio-Rad, Hercules, CA) was used to identify MMP-9. All original blots are provided in the supplementary file.

\section{Measurement of plasma ROS}

The rat plasma was incubated with $100 \mu \mathrm{M}$ dichlorofluorescein diacetate (DCFDA; Invitrogen, Carlsbad, CA, USA) in dark for $10 \mathrm{~min}$ at $37^{\circ} \mathrm{C}$. Fluorescence intensity was recorded using excitation and emission wavelengths of 485/520 nm in a Synergy 2 Multi-Mode Microplate Reader (Bio-Tek, Winooski, VT). The plasma malondialdehyde (MDA), a lipid peroxidation product, was quantified by measuring thiobarbituric acid reactive substances (TBARS) formation as described 
previously [54]. 1, 1, 3, 3-tetraethoxypropane was used as the standard to calculate MDA content (nmoles $/ \mathrm{ml}$ ).

\section{Statistical analysis}

The results are presented as mean \pm S.E.M. Statistical significance was defined as $p \leq 0.05$ and determined using the student's $t$-test (normally-distributed data) and the Mann-Whitney U-test (nonparametric data).

\section{ACKNOWLEDGMENTS}

This work was supported by the National Institutes of Health (K08-DK081479) and Medical College of Georgia (SK). We thank Dr. Zsolt Bagi (Vascular Biology Center, Medical College of Georgia) for providing the rat vascular smooth muscle cells. All authors have no competing financial interest and have read the journal's authorship agreement and policy on disclosure of potential conflicts of interest.

\section{CONFLICTS OF INTEREST}

The authors declare that they have no conflicts of interest.

\section{Editorial note}

This paper has been accepted based in part on peerreview conducted by another journal and the authors' response and revisions as well as expedited peer-review in Oncotarget.

\section{REFERENCES}

1. Moller S, Christensen E, Henriksen JH. Continuous blood pressure monitoring in cirrhosis. Relations to splanchnic and systemic haemodynamics. J Hepatol. 1997; 27:284-294.

2. Bosch J, Garcia-Pagan JC. Complications of cirrhosis. I. Portal hypertension. J Hepatol. 2000; 32(1 Suppl):141-156.

3. Forrest EH, Jalan R, Hayes PC. Review article: renal circulatory changes in cirrhosis-pathogenesis and therapeutic prospects. Aliment Pharmacol Ther. 1996; 10:219-231

4. Tazi KA, Barriere E, Moreau R, Heller J, Sogni P, Pateron D, Poirel O, Lebrec D. Role of shear stress in aortic eNOS up-regulation in rats with biliary cirrhosis. Gastroenterology. 2002; 122:1869-1877.

5. Atucha NM, Ortiz MC, Fortepiani LA, Nadal FJ, MartinezPrieto C, Garcia-Estan J. Mesenteric hyporesponsiveness in cirrhotic rats with ascites: role of cGMP and $\mathrm{K}+$ channels. Clin Sci (Lond). 2000; 99:455-460.

6. Ralevic V, Mathie RT, Moore KP, Burnstock G. Vasoconstrictor responsiveness of the rat mesenteric arterial bed in cirrhosis. Br J Pharmacol. 1996; 118:435-441.

7. Niederberger M, Gines P, Martin PY, Tsai P, Morris K, McMurtry I, Schrier RW. Comparison of vascular nitric oxide production and systemic hemodynamics in cirrhosis versus prehepatic portal hypertension in rats. Hepatology. 1996; 24:947-951.

8. Hennenberg M, Trebicka J, Biecker E, Schepke M, Sauerbruch T, Heller J. Vascular dysfunction in human and rat cirrhosis: role of receptor-desensitizing and calciumsensitizing proteins. Hepatology. 2007; 45:495-506.

9. Falloon BJ, Stephens N, Tulip JR, Heagerty AM. Comparison of small artery sensitivity and morphology in pressurized and wire-mounted preparations. Am J Physiol. 1995; 268:H670-678.

10. Hill MA, Sun Z, Martinez-Lemus L, Meininger GA. New technologies for dissecting the arteriolar myogenic response. Trends Pharmacol Sci. 2007; 28:308-315.

11. Hill MA, Meininger GA, Davis MJ, Laher I. Therapeutic potential of pharmacologically targeting arteriolar myogenic tone. Trends Pharmacol Sci. 2009; 30:363-374.

12. Khurana S, Raina H, Pappas V, Raufman JP, Pallone TL. Effects of deoxycholylglycine, a conjugated secondary bile acid, on myogenic tone and agonist-induced contraction in rat resistance arteries. PLoS One. 2012; 7:e32006.

13. Jadeja RN, Rachakonda V, Bagi Z, Khurana S. Assessing Myogenic Response and Vasoactivity In Resistance Mesenteric Arteries Using Pressure Myography. J Vis Exp. 2015.

14. Rashid SK, Khodja NI, Auger C, Alhosin M, Boehm N, Oswald-Mammosser M, Schini-Kerth VB. Probiotics (VSL\#3) prevent endothelial dysfunction in rats with portal hypertension: role of the angiotensin system. PLoS One. 2014; 9:e97458

15. Yang W, Zhang J, Hu B, Wu W, Venter J, Alpini G, Fallon MB. The role of receptor tyrosine kinase activation in cholangiocytes and pulmonary vascular endothelium in experimental hepatopulmonary syndrome. American journal of physiology Gastrointestinal and liver physiology. 2014; 306:G72-80.

16. Grace JA, Klein S, Herath CB, Granzow M, Schierwagen R, Masing N, Walther T, Sauerbruch T, Burrell LM, Angus PW, Trebicka J. Activation of the MAS receptor by angiotensin-(1-7) in the renin-angiotensin system mediates mesenteric vasodilatation in cirrhosis. Gastroenterology. 2013; 145:874-884 e875.

17. Reiberger T, Payer BA, Schwabl P, Hayden H, Horvatits T, Jager B, Hummel T, Mitterhauser M, Trauner M, Fuhrmann V, Angermayr B, Peck-Radosavljevic M, Vienna Hepatic Hemodynamic L. Nebivolol treatment increases splanchnic blood flow and portal pressure in cirrhotic rats via modulation of nitric oxide signalling. Liver international. 2013; 33:561-568.

18. Herath CB, Lubel JS, Jia Z, Velkoska E, Casley D, Brown L, Tikellis C, Burrell LM, Angus PW. Portal pressure 
responses and angiotensin peptide production in rat liver are determined by relative activity of ACE and ACE2. American journal of physiology Gastrointestinal and liver physiology. 2009; 297:G98-G106.

19. Wiest R, Groszmann RJ. The paradox of nitric oxide in cirrhosis and portal hypertension: too much, not enough. Hepatology. 2002; 35:478-491.

20. Tsai MH, Jiang MJ. Rho-kinase-mediated regulation of receptor-agonist-stimulated smooth muscle contraction. Pflugers Arch. 2006; 453:223-232.

21. Pang H, Guo Z, Su W, Xie Z, Eto M, Gong MC. RhoA-Rho kinase pathway mediates thrombin- and U-46619-induced phosphorylation of a myosin phosphatase inhibitor, CPI-17, in vascular smooth muscle cells. Am J Physiol Cell Physiol. 2005; 289:C352-360.

22. Chitaley K, Webb RC. Nitric oxide induces dilation of rat aorta via inhibition of rho-kinase signaling. Hypertension. 2002; 39:438-442.

23. Young AR, Saveland H, Pickard JD, Perry S, Brandt L, Ljunggren B. Early effects of tetraethylammonium chloride on the contractile properties of isolated rabbit basilar arteries. J Cereb Blood Flow Metab. 1987; 7:237-247.

24. Ledoux J, Werner ME, Brayden JE, Nelson MT. Calciumactivated potassium channels and the regulation of vascular tone. Physiology (Bethesda). 2006; 21:69-78.

25. Hill MA, Yang Y, Ella SR, Davis MJ, Braun AP. Large conductance, $\mathrm{Ca} 2+$-activated $\mathrm{K}+$ channels $(\mathrm{BKCa})$ and arteriolar myogenic signaling. FEBS Lett. 2010; 584:20332042.

26. Yeon SI, Kim JY, Yeon DS, Abramowitz J, Birnbaumer L, Muallem S, Lee YH. Transient receptor potential canonical type 3 channels control the vascular contractility of mouse mesenteric arteries. PLoS One. 2014; 9:e110413.

27. Dietrich A, Mederos YSM, Gollasch M, Gross V, Storch U, Dubrovska G, Obst M, Yildirim E, Salanova B, Kalwa H, Essin K, Pinkenburg O, Luft FC, et al. Increased vascular smooth muscle contractility in TRPC6-/- mice. Mol Cell Biol. 2005; 25:6980-6989.

28. Dal-Ros S, Oswald-Mammosser M, Pestrikova T, Schott C, Boehm N, Bronner C, Chataigneau T, Geny B, Schini-Kerth VB. Losartan prevents portal hypertension-induced, redoxmediated endothelial dysfunction in the mesenteric artery in rats. Gastroenterology. 2010; 138:1574-1584.

29. Maneen MJ, Cipolla MJ. Peroxynitrite diminishes myogenic tone in cerebral arteries: role of nitrotyrosine and F-actin. Am J Physiol Heart Circ Physiol. 2007; 292:H1042-1050.

30. Henriksen JH, Moller S. Liver cirrhosis and arterial hypertension. World journal of gastroenterology. 2006; 12:678-685.

31. Hanje AJ, Patel T. Preoperative evaluation of patients with liver disease. Nat Clin Pract Gastroenterol Hepatol. 2007; 4:266-276.

32. Chen YC, Gines P, Yang J, Summer SN, Falk S, Russell NS, Schrier RW. Increased vascular heme oxygenase-1 expression contributes to arterial vasodilation in experimental cirrhosis in rats. Hepatology. 2004; 39:10751087.

33. Abraldes JG, Pasarin M, Garcia-Pagan JC. Animal models of portal hypertension. World journal of gastroenterology. 2006; 12:6577-6584.

34. Schubert R, Mulvany MJ. The myogenic response: established facts and attractive hypotheses. Clin Sci (Lond). 1999; 96:313-326.

35. Lucas KA, Pitari GM, Kazerounian S, Ruiz-Stewart I, Park J, Schulz S, Chepenik KP, Waldman SA. Guanylyl cyclases and signaling by cyclic GMP. Pharmacol Rev. 2000; 52:375-414.

36. Surks HK, Mochizuki N, Kasai Y, Georgescu SP, Tang KM, Ito M, Lincoln TM, Mendelsohn ME. Regulation of myosin phosphatase by a specific interaction with cGMPdependent protein kinase Ialpha. Science. 1999; 286:15831587.

37. Annie-Jeyachristy S, Geetha A, Surendran R, Sundaram A, Lavanya K, Kumar SJ, Prakash SA. Level of nitrated proteins in the plasma, platelets and liver of patients with liver cirrhosis. Redox Rep. 2009; 14:259-266.

38. Jackson WF. Ion channels and vascular tone. Hypertension. 2000; 35:173-178.

39. Welsh DG, Morielli AD, Nelson MT, Brayden JE. Transient receptor potential channels regulate myogenic tone of resistance arteries. Circ Res. 2002; 90:248-250.

40. Blanco-Rivero J, Marquez-Rodas I, Sastre E, Cogolludo A, Perez-Vizcaino F, del Campo L, Nava MP, Balfagon G. Cirrhosis decreases vasoconstrictor response to electrical field stimulation in rat mesenteric artery: role of calcitonin gene-related peptide. Experimental physiology. 2011; 96:275-286.

41. Kim HY, Seok YM, Woodman OL, Williams SJ, Kim IK. 3',4'-Dihydroxyflavonol reduces vascular contraction through $\mathrm{Ca}(2)(+)$ desensitization in permeabilized rat mesenteric artery. Naunyn Schmiedebergs Arch Pharmacol. 2012; 385:191-202.

42. Zacharia J, Mauban JR, Raina H, Fisher SA, Wier WG. High vascular tone of mouse femoral arteries in vivo is determined by sympathetic nerve activity via alpha1Aand alpha1D-adrenoceptor subtypes. PLoS One. 2013; 8:e65969.

43. Wilson DP, Susnjar M, Kiss E, Sutherland C, Walsh MP. Thromboxane A2-induced contraction of rat caudal arterial smooth muscle involves activation of $\mathrm{Ca} 2+$ entry and $\mathrm{Ca} 2+$ sensitization: Rho-associated kinase-mediated phosphorylation of MYPT1 at Thr-855, but not Thr-697. Biochem J. 2005; 389:763-774.

44. Carter RW, Begaye M, Kanagy NL. Acute and chronic NOS inhibition enhances alpha(2)- adrenoreceptor-stimulated RhoA and Rho kinase in rat aorta. Am J Physiol Heart Circ Physiol. 2002; 283:H1361-1369.

45. Resch M, Wiest R, Moleda L, Fredersdorf S, Stoelcker B, 
Schroeder JA, Scholmerich J, Endemann DH. Alterations in mechanical properties of mesenteric resistance arteries in experimental portal hypertension. American journal of physiology Gastrointestinal and liver physiology. 2009; 297:G849-857.

46. Bigg HF, Rowan AD, Barker MD, Cawston TE. Activity of matrix metalloproteinase-9 against native collagen types I and III. The FEBS journal. 2007; 274:1246-1255.

47. Fernandez-Varo G, Morales-Ruiz M, Ros J, Tugues S, Munoz-Luque J, Casals G, Arroyo V, Rodes J, Jimenez W. Impaired extracellular matrix degradation in aortic vessels of cirrhotic rats. J Hepatol. 2007; 46:440-446.

48. Jiang JX, Chen X, Serizawa N, Szyndralewiez C, Page P, Schroder K, Brandes RP, Devaraj S, Torok NJ. Liver fibrosis and hepatocyte apoptosis are attenuated by GKT137831, a novel NOX4/NOX1 inhibitor in vivo. Free Radic Biol Med. 2012; 53:289-296.

49. Aller M-A, Arias J-L, Prieto I, Arias J. A suitable microsurgical method for obstructive cholestasis in the rat. Protocol Exchange. 2010.
50. Dougherty PJ, Davis MJ, Zawieja DC, Muthuchamy M. Calcium sensitivity and cooperativity of permeabilized rat mesenteric lymphatics. Am J Physiol Regul Integr Comp Physiol. 2008; 294:R1524-1532.

51. Raffetto JD, Khalil RA. $\mathrm{Ca}(2+)$-dependent contraction by the saponoside escin in rat vena cava: implications in venotonic treatment of varicose veins. J Vasc Surg. 2011; 54:489-496.

52. Cho YE, Ahn DS, Morgan KG, Lee YH. Enhanced contractility and myosin phosphorylation induced by $\mathrm{Ca}(2+)$-independent MLCK activity in hypertensive rats. Cardiovasc Res. 2011; 91:162-170.

53. Posa A, Szabo R, Kupai K, Barath Z, Szalai Z, Csonka A, Veszelka M, Gyongyosi M, Radak Z, Menesi R, Pavo I, Berko AM, Varga C. Cardioprotective effects of voluntary exercise in a rat model: role of matrix metalloproteinase-2. Oxid Med Cell Longev. 2015; 2015:876805.

54. Buege JA, Aust SD. Microsomal lipid peroxidation. Methods Enzymol. 1978; 52:302-310. 